\title{
Bank Buildings, Belfast, UK: making safe after a fire
}

\section{Tim Lohmann}

Director, Wentworth House Partnership, Esher, UK

(Orcid:0000-0001-8139-271X) (corresponding author:

tim.lohmann@wentworth-house.co.uk)

\section{John McClafferty}

Operations Director, Keltbray, Esher, UK

In August 2018, a fire badly damaged a listed building in the centre of Belfast. This left the perimeter walls standing and the inside largely destroyed. Because of the dangerous nature of the structure, the surrounding area was closed. This paper describes the engineering aspects of the approach to making the remaining structure safe to allow the surrounding area to reopen and to start the rebuilding works on the retained building. The design approach to the public safety cordon involved the use of empirical techniques, as well as advanced simulation software. The design approach for the facade-retention scheme was complicated by the poor ground and buried services, as well as having to allow for installation with no access inside the building. The solution involved the use of shipping containers as structural components, as well as fibre-reinforced foundation rafts. The scheme has been successfully installed, and access to the city centre has been reinstated.

\section{Introduction}

Bank Buildings is a prominent building in the centre of Belfast. It is one of the earliest iron-framed buildings in Ireland and was constructed around 1895-1900. The structure was originally of castiron columns, wrought-iron beams and timber floors, with a perimeter wall of brick and stone facings. During the troubles, the side elevation onto Bank Street was damaged by a bomb, and this prompted some rebuilding with a partial steel frame to the north-west part of the building. A further refurbishment was underway in 2018 when a fire took place (Figure 1), which largely destroyed the internal structure of the building. The timber floors and existing frame to the centre of the front part of the building collapsed, leaving the walls free-standing. The rebuilt frame to the rear of the building remained largely standing but severely damaged by the fire.

As a consequence of the fire, the area surrounding the building both roads and buildings - was closed by the local authority until the building could be made safe. The initial view was to demolish the building as soon as possible to make it safe, but the view was that the heritage importance of the building meant that if it could be saved, then this was the priority. Once this had been decided, there was a series of activities to take place to ensure public safety and to preserve the remaining structure where possible. Once the structure was made safe, the demolition of the remaining fabric within the building and the subsequent rebuilding activities were facilitated.

The building is rectangular running east-west. The eastern (front) face is onto the junction of Royal Avenue and Castle Place (Figure 2). The northern face is along the narrow Bank Street and the southern face along Castle Street. The western (back) face abuts another building. The building was generally four storeys (approximately $18 \mathrm{~m}$ ) high with a cornice running around at the top of this level. Above this, there was a series of chimneys on the side elevations extending around a further $4 \mathrm{~m}$. Around the eastern end of the building, the side elevations stepped up by a level, with a decorative railing above that, and on the front elevation, this was further extended by a large central clock feature. In the original condition, the facade was restrained by the internal framing, which was largely lost in the fire (Figure 3).

This paper describes the engineering approaches taken to making the building safe and supporting the free-standing facades. It does not cover the heritage works or the rebuilding activities that will take place following the enabling works, which consist of the making the building safe, demolition of the remaining internal structure and preparation for piling works.

At the time of writing this paper, the surrounding roads and buildings have been largely reopened, the facade-retention system and tower cranes have been installed and the demolition works to the inside of the building are underway. Reconstruction is expected to start in late 2019. The works were undertaken by Keltbray, and the design work was by Wentworth House Partnership, in conjunction with their independent checkers, Expedition.

\section{Sequence of activities}

Following the fire, the sequence of activities for the preservation of the building was broadly

- reducing the risk to the public by designing and installing a protective cordon

- reducing the risk to both the structure and the public by removing the slender and damaged elements above the cornice at the fourth floor

- reducing the risk to the structure by designing and installing the facade-retention system

- gaining access to the building to enable the demolition of the damaged internal structures and debris. 


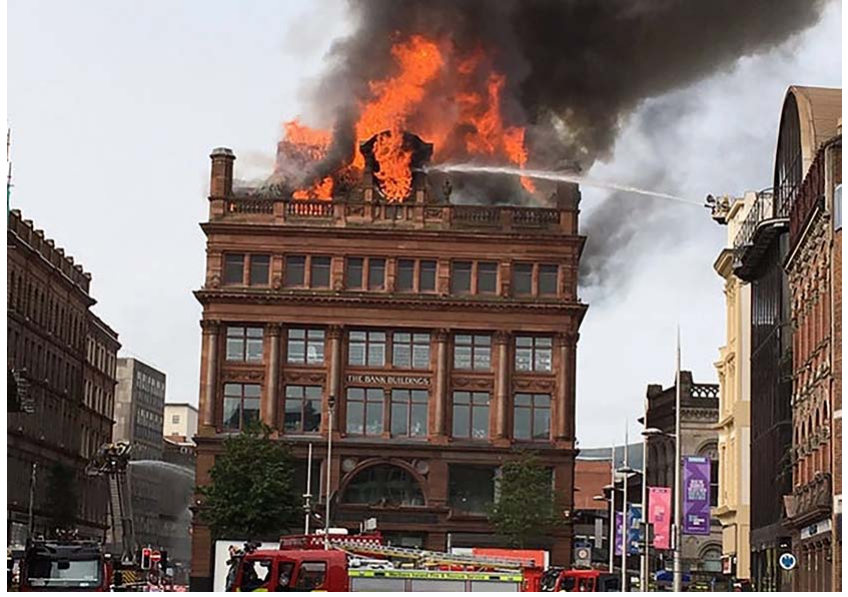

Figure 1. Bank Buildings during the fire

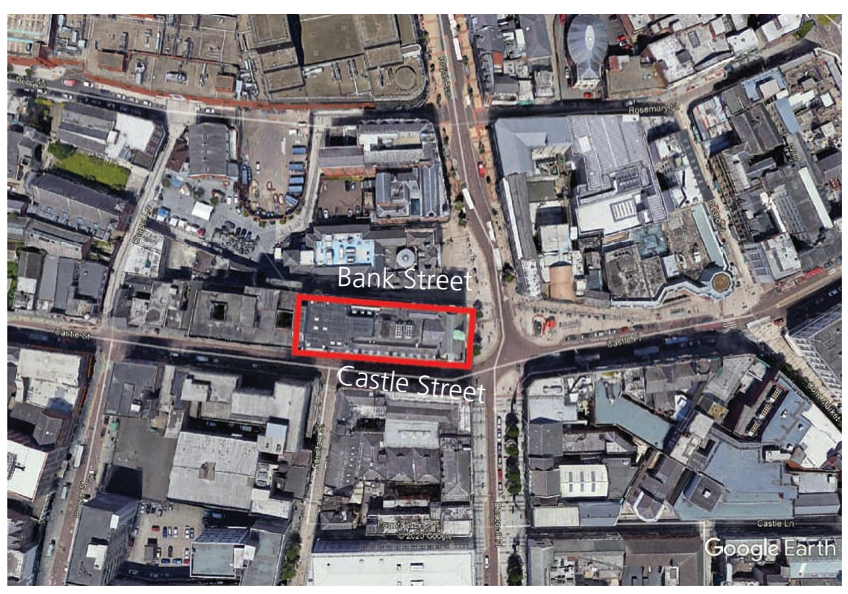

Figure 2. Location of Bank Buildings

\section{Challenges}

The normal practice for a facade retention is that the design is concluded before the demolition work starts. Similarly, there is access to a typical facade from both inside and out and the foundations can be placed around any services. If the surrounding streets do not give enough space for gravity foundations, then piles can be placed around the known services. In this scheme, there was no opportunity to secure the facade retention before removing the structure. Similarly, the condition of the facade meant that piling externally was not feasible.

One of the main challenges with this scheme was that the demolition had been nearly concluded by the fire before any design could start. No safe access was available to the inside of the building, apart from using man-riding cranes from outside the building footprint. There was not an opportunity to dig slit trenches to locate the services - although there were recent services drawings. The ground conditions around the site were

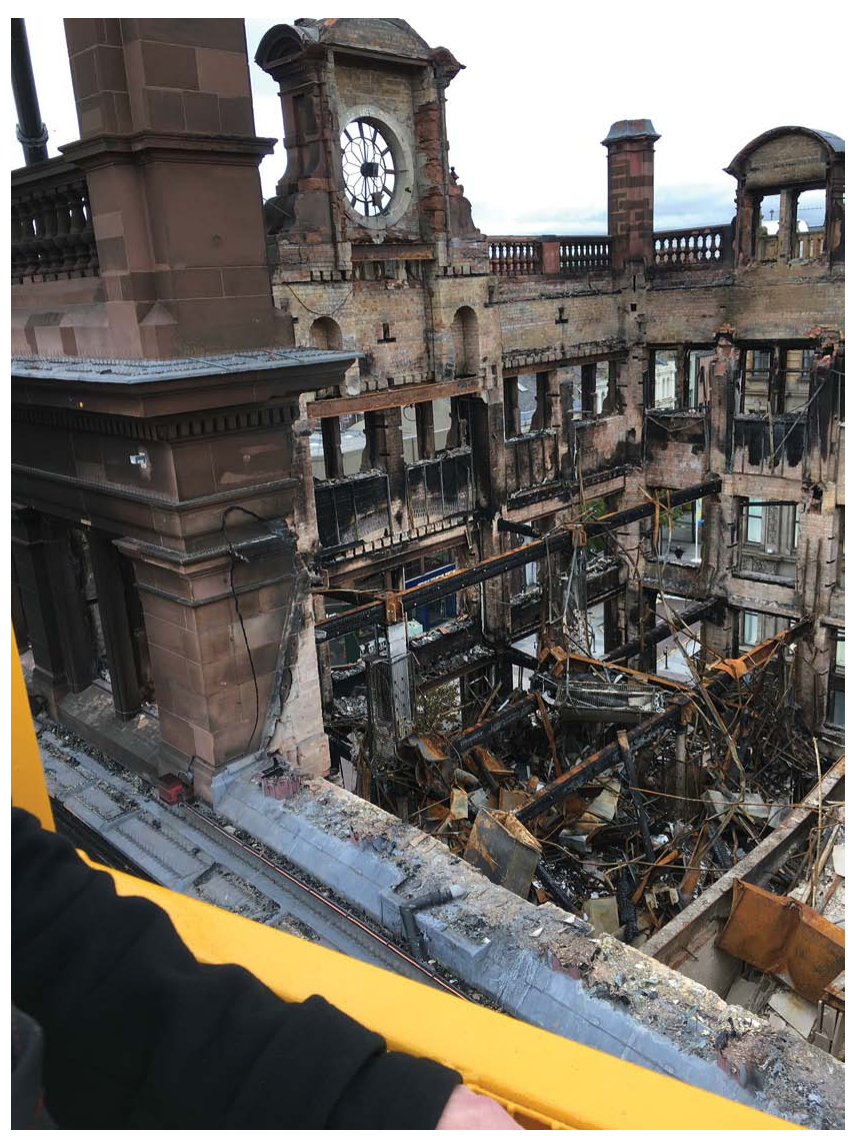

Figure 3. Fire-damaged east elevation from inside

poor, with a weak, alluvial material to a significant depth. This was derived from previous local boreholes and proved with cone penetration testing $(\mathrm{CPT})$ during the works.

In addition, there were constraints from the local drive to reopen streets and businesses, the heritage issues associated with a landmark building and the safety concerns about working in and around a dangerous structure in an unknown condition.

\section{Modelling and analysis approach}

A decision was taken very early to develop a model for the building and to use this as the basis of the analysis and design. The shape of the existing structure was laser-scanned, and this was used as the basis of the design. This was imported into the Tekla Structures software program, and the key elements were located in this from basic hand calculations. This model then formed the basis of the rest of the design work and was refined as work progressed.

The loads onto the support structure were derived from the wind study and the suggested eccentricities from Building Research Establishment (BRE) guidance (Kusotova and Breeze, 2019). In addition, an allowance was made for additional eccentricity where the geometry of the structure required it. The worst of these two conditions was taken for the analysis. 
The analysis of the support structure was derived from the same model, and this fed the structural design in the Tekla Building Designer software program, where the members could be sized. The connection design was derived from this analysis model. The support structure was formed from trusses spanning between towers supported on pad foundations.

Once the members and connections had been designed, the model was developed into a set of construction issue drawings and the fabrication packages were prepared directly from the same model. This model contained the scan of the existing structure and the detail of the retention and foundation schemes (Figure 4).

The only challenge with this was that the model took the ground surface as level rather than reflecting the sloping conditions. The assumption was that the top of foundations would be formed to a constant level and that this would deal with the varying ground levels. In the event, the site team formed the foundations to a constant thickness and this meant that some spacers had to be introduced in the towers on Bank Street.

\section{Reducing the height}

The building had some high-level features that the fire had left free-standing. These included chimneys along the side elevations, a raised pediment around the front part of the sides and the front elevation and a central clock feature.

The damage caused by the fire had left these in a precarious condition, as the restraining roof behind had been largely burnt away and some embedded timbers had been destroyed. While these were important from a heritage point of view, supporting them was going to be very awkward and their height meant that they posed a falling-object risk to those working below and the wider public. As such, a decision was taken, in conjunction with the heritage team and the local authority, to reduce the height of the building by removing these.

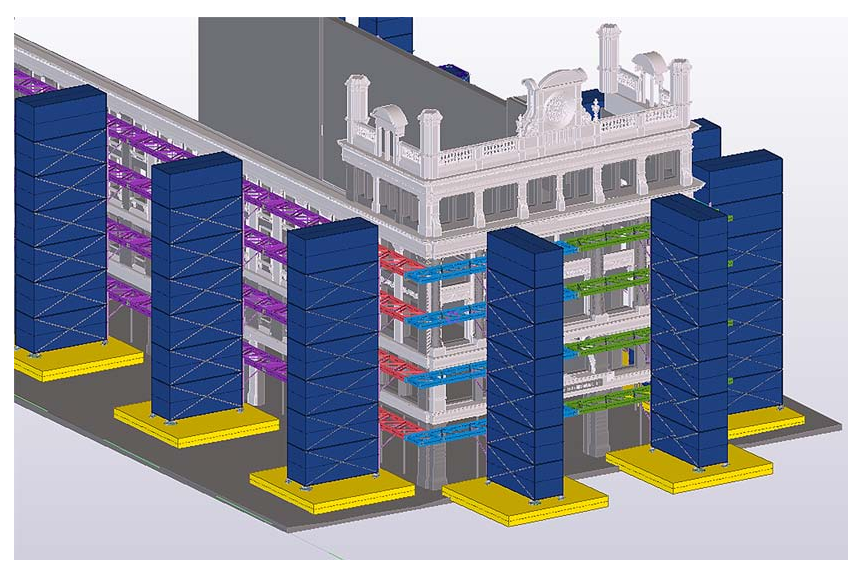

Figure 4. Extract from model showing scanned facade and retention structure
The removal was undertaken by experienced teams working from both a crane-suspended basket and a working platform on a groundlevel teleporter. This facilitated the recording of the condition of the elements and then dismantling them stone by stone, keeping those that were in good enough condition and labelling them for conservation or replacement. The process was to photograph the structures to identify the location of each stone, then to number each stone as it was removed, record this on the photographs and then to pallet the stone and send away for storage and conservation.

The sequence adopted was to remove the chimneys at the sides first and then reduce the front elements in layers from the top. Most of the stone was salvaged, and the brick masonry was disposed of. The hazards associated by working at height around a precarious structure were mitigated by limiting the wind speed in which work could take place and by installing tilt monitoring on the various elements.

\section{Public protection cordon}

One of the concerns about reopening streets and businesses around the damaged building was the shape of a likely debris field following a full or partial collapse and the velocity/energy profile of the debris during that collapse. Immediately following the fire, an exclusion zone around one and a half times the height of the building was established by the local authority (BSI, 2011a). Since the drive was to reopen pedestrian access from Royal Avenue to Donegall Place, by way of Castle Street, and the surrounding businesses, a way of moving this line closer to the building had to be established.

The solution was in two parts: firstly, to reduce the height of the building to a common level by removing the less stable high-level parts and, secondly, a protective wall designed to capture any flying debris from a collapse and to resist the lateral loads from that debris was designed and installed.

The question here was how much lateral load should be expected from a collapsing masonry facade at different distances from the facade. This is not a field with much published information, as much of the research on collapsing masonry facades is on the collapse itself rather than the aftermath and the distribution of the debris. This was looked at in several ways, by treating the debris as a fluid with a density equivalent to that of the solid masonry and allowing the load profile associated with a wave of twice the predicted depth hitting the cordon. The checkers looked at the mechanics of falling stacks of blocks, and their independent consultants looked at simulating the collapse with non-linear tools to get to their predicted fields. These approaches were all combined, and the findings of the options were discussed with the local authority and their checker.

The solution adopted was to install a level mat of crushed stone and then to support a wall of stone-ballasted shipping containers in a $U$ shape around the front of the building. It was felt that it was not feasible to install walls along the sides, as the roads were too narrow to allow a facade retention and cordon. The cordon structure was of $20^{\prime}(6.1 \mathrm{~m})$ shipping containers aligned along the 


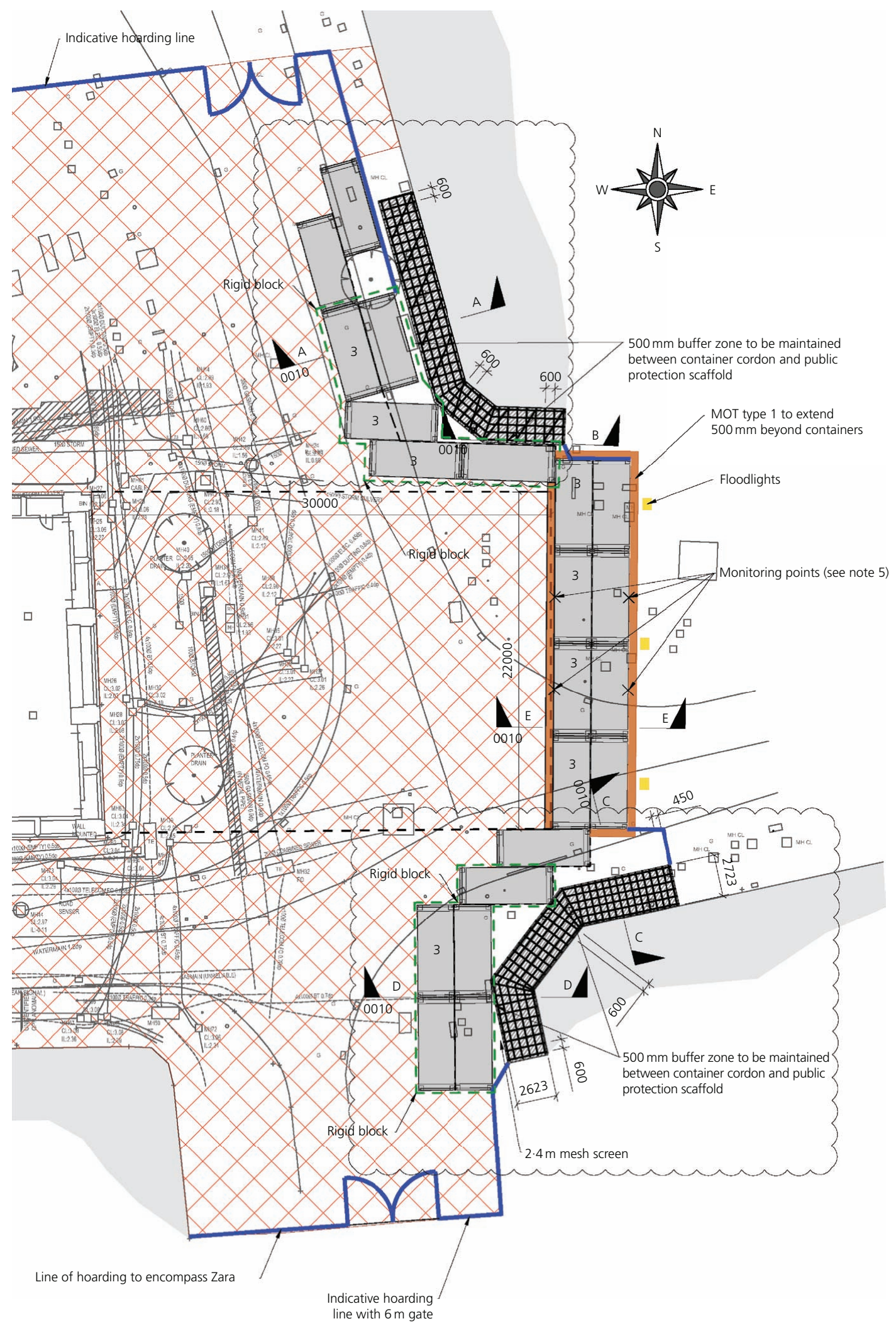

Figure 5. Plan of the protection cordon (units are $\mathrm{mm}$ for plan dimensions) 
length of the $\mathrm{U}$ in a stack 2 containers high and 2 containers wide. This gave a $16^{\prime}(4.88 \mathrm{~m}) \times 16^{\prime}$ block, and in addition, a debris net fence was formed a further $8^{\prime}(2.44 \mathrm{~m})$ above this (Figure 5). The system allowed pedestrian access through the corners between Royal Avenue and Castle Place and Castle Place and Donegall Place. It also meant that the exclusion zone could be moved into the line of the cordon. The pedestrian access was through tunnels formed with a scaffold with the roofs designed as resilient platforms for a nominal $10 \mathrm{kPa}$ load.

The use of shipping containers was determined by the local availability of containers and stone as ballast. There are standard container sizes, and their structural performance is set according to ISO 1946-1 (ISO, 1990). In addition, there are widely available connectors for providing structural connections between the corner nodes of the containers. The containers are designed to transmit loads primarily through these corner nodes.

In order to calibrate the foundation design for the main facaderetention system, level monitoring was installed on the inside and outside of the cordon to determine the effect of the weight of the ballasted containers on the ground. This showed settlements on the order of $10 \mathrm{~mm}$ as the cordon was built, and these remained stable at this until the cordon was removed.

\section{Facade-retention system}

The facade-retention system was novel, as it had to be installed from outside only and access around the facade was limited by concerns over the stability of the remaining structure. The usual local practice for foundations would be to drive tubular steel piles through the alluvium. However, this had the significant problems of the vibration that this would cause to the fragile structure and how access could be provided for the works adjacent to the unsupported facade. To avoid having to pile the foundations, it was decided to use spread raft foundations. In order to minimise the work content associated with assembling the main support towers, a system (Figure 4) was designed using ballasted shipping containers supporting modular trusses with the facade tied to these.

The wind loads onto the facade-retention system (Figure 6) were derived from the code requirements (BS EN 1991-1-4 (BSI, 2005)) and then verified and refined by a wind tunnel study commissioned by BRE. It was felt that the complexity of the environment and the condition of the structure meant that this was a valuable exercise. While the time frame meant that the wind tunnel work was carried on in parallel with the design of the main elements, it gave reassurance that the global design was safe and enabled the designer to refine the global loads downwards and enhance some of the members in critical locations identified by the results.

The towers were generally formed from $20^{\prime}(6.10 \mathrm{~m})$ shipping containers (Figure 7), ballasted with local stone and stacked with their long axis perpendicular to the facade. Along Bank Street, the width of the road limited the size of the towers to $10^{\prime}(3.05 \mathrm{~m})$ containers, and these were placed closer together. The towers were seven containers high - about $17.5 \mathrm{~m}$ on top of the foundations. They were connected with proprietary lashing equipment, and this meant that the erection of the towers was simple, as they could be pre-ballasted and then lifted into position and connected with four simple locks.

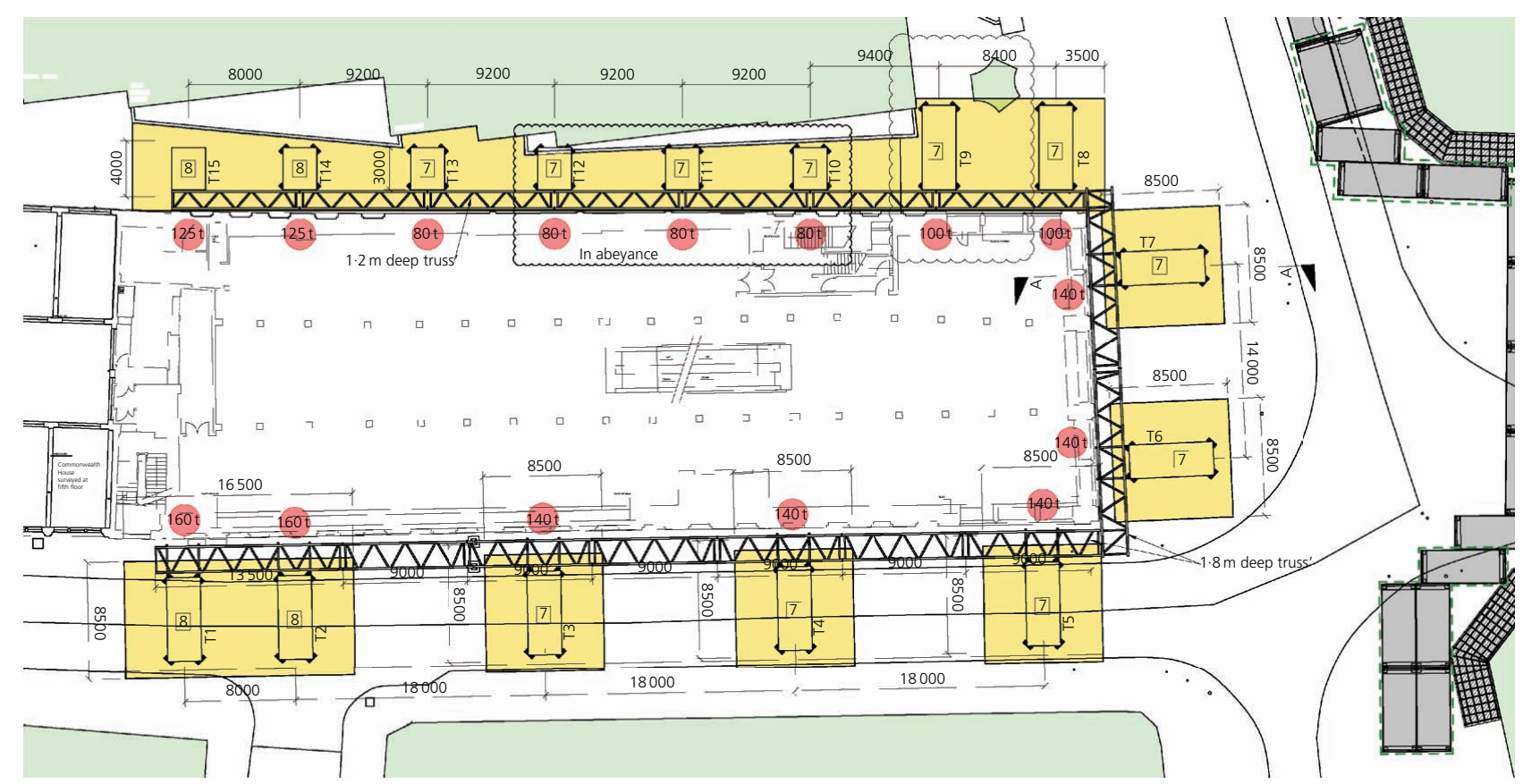

Figure 6. Plan of the facade-restraint system (units are in $\mathrm{mm}$ ) 


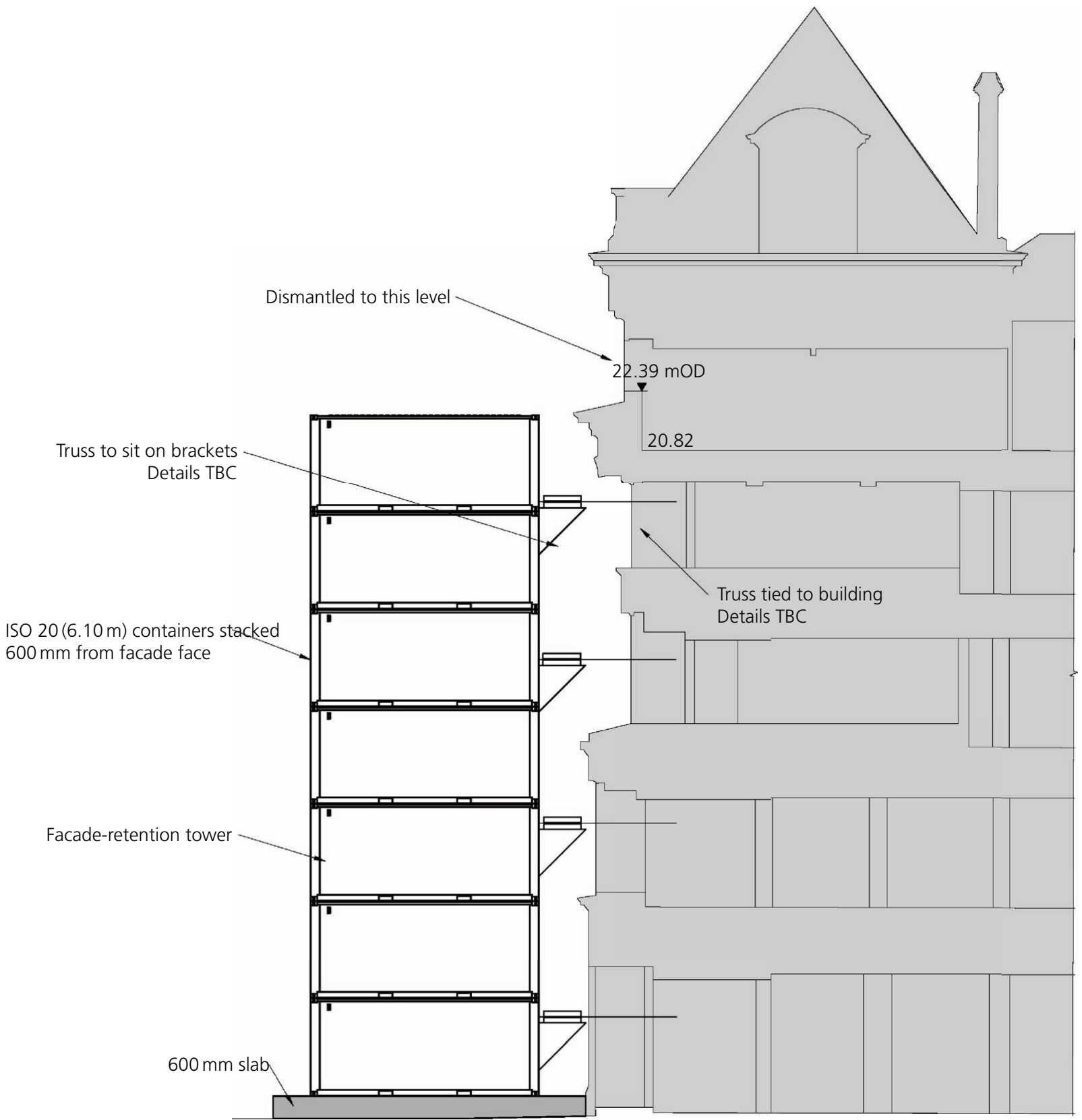

Figure 7. Typical section through the façade-restraint system on Castle Street. mOD, m above Ordnance Datum

The foundation detail was a post-fixed resin-anchored fixture that had bolts extending above the top to allow for future jacking. The necessity for a jacking provision came from the possibility of settlement of the foundations causing rotation of the system, leading to instability. The level and rotation of the base were monitored by simple level checks on the four corners to determine the necessity for any remedial jacking, but so far none has been required. Along the southern and front elevations, it was possible to span the trusses $18 \mathrm{~m}$, which was limited by the capacity of the ballasted foundations. Along the northern elevation, the reduced width of Bank Street meant that this was limited to $9 \mathrm{~m}$.
During the design checks, it became clear that not all containers are the same and that some have a substantially higher design capacity for lateral load than the others. Consequently, once work on the erection of towers had started, it was necessary to supplement the racking strength of the lower containers with external strap bracing.

The facade trusses were formed from 9 m modules. Each module was formed with main chords of universal beam members standing vertically, and these chords were braced with diagonal members of equal-angle section between both top and bottom 
webs. The trusses were sized for stiffness, and there were two sizes of truss for the $18 \mathrm{~m}$ span and the $9 \mathrm{~m}$ span. In order to avoid a trapping risk and to move the splice from the main moments, the splices were located at approximately one-fourth spans. The trusses were set to the highest clear opening below each floor level. As the floor heights varied, this meant that the spacing was not regular and that the lower trusses carried a larger height of floor.

The trusses were supported on angle brackets welded to the hard points on the containers, and these varied, as the joints in the containers did not align with the vertical spacing of the trusses.

\section{Foundations}

The ground at the site was relatively unknown and anecdotally is formed from made ground overlying a soft alluvial material to depth. There was no opportunity for a full site investigation due to the constraints of the structure and the preference to avoid percussion nearby. It was possible to undertake three CPT tests to depth using a ballasted lorry mounted probe. The results from the CPT confirmed the poor quality of the ground (Causeway Geotech, 2018). In order to minimise the settlement, large pad footings were designed with a limiting increase in dead load on the ground of $120 \mathrm{kPa}$. This gave pads around $9 \mathrm{~m} \times 9 \mathrm{~m}$ along the south and east elevations and a continuous raft along the northern elevation. There was much discussion about how to review the effect of the wind on the foundations, and the approach adopted was that the wind would be considered in the ultimate limit states but not in the settlement serviceability limit state. This was because the peak wind load is a transient short-term phenomenon and the soil settlement response is a longer-term drainage-related process. It was agreed that this would be monitored.

The big challenge with the ground was how to predict and control deflections, of both the structure and the buried services. The site investigation had provided parameters for a three-dimensional (3D) finite-element study of the time-related deflection profile of the ground, at the surface and at depth. This gave upper-bound values for the peak deflections and identified any services that were thought to be at risk. For each of the main services, it was possible to extract a predicted deflected shape and then to assess the potential damage to it (Figure 8). When combined with surface monitoring, this then enables a comparison of the actual deflection at the surface with the modelled behaviour and so identify which, if any, services would be at risk. Because of the unusual conditions on-site, the priority was the preservation of the building rather than the services. A strategy was developed for the termination of services in the event of large deflections, but this was not needed to be implemented.

In the event, the measured deflections at the ground level have been much lower than predicted, the understanding is that the main reason for this is that the road and footway finishes are deeper and stiffer than modelled and give a much better lateral spread of the load.

The foundations consisted of three broad elements, the isolated pad foundations for the $20^{\prime}(6.10 \mathrm{~m})$ container towers, the continuous raft foundation for the $10^{\prime}(3.05 \mathrm{~m})$ container towers

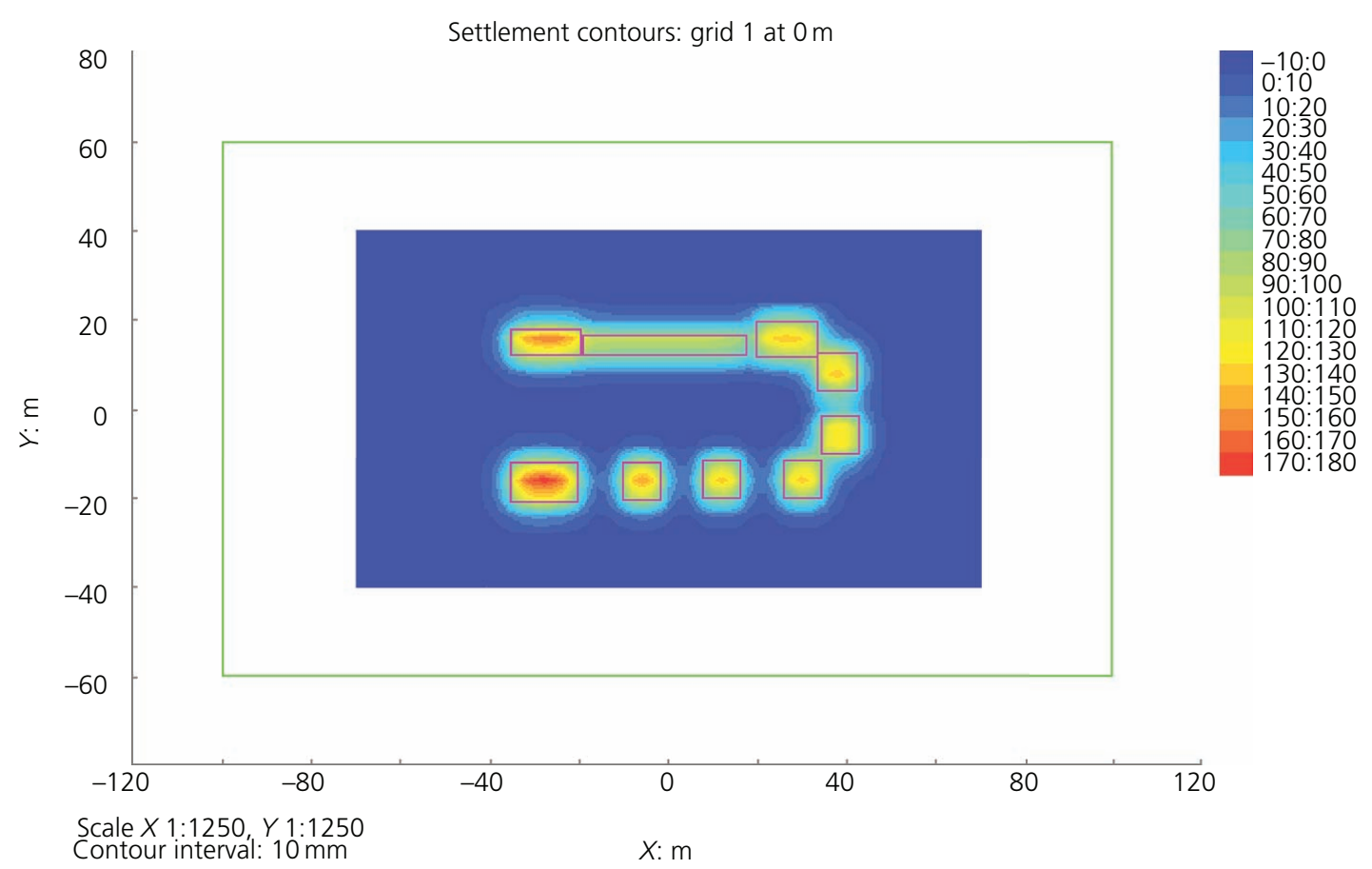

Figure 8. Predicted settlement profile at the ground level 
on Bank Street and the two tower crane foundations. In addition to spreading the foundation loads from the towers, the bases formed part of the kentledge for the system and so they were relatively thick $(800 \mathrm{~mm})$ foundations for the towers. The force actions from the towers were relatively low for bases this thick, and it was possible to use steel-fibre-reinforced concrete rather than traditional reinforcement for these elements. This gave the advantage of not having as much work under the unsupported facade as well as speeding up the process. One of the issues with the lack of a top mat in a thick slab is that there is no access for operatives while the concrete is placed. However, placing the concrete was made possible using a fluid mix and pumping this. The key design issue was the local failure of the holding-down bolts, and the fibre reinforcement significantly enhanced the pullout resistance, which was verified by testing.

To service the demolition of the remains of the inside of the building, two tower cranes were required. The tower crane foundations were designed as simple gravity foundations with the base depth set by the anchor depth and the plan dimensions by the limiting ground bearing pressure. These were designed in accordance with the recently revised tower crane foundation guidance from the Construction Industry Research and Information Association (Ciria, 2019). These were traditionally reinforced, as they were to be erected after the main towers were up and there is no experience on the use of fibrereinforced foundations for tower cranes.

\section{Installation sequence}

The sequence of the installation of the facade-retention scheme was broadly as follows. The work all took place from within the compound formed by the pedestrian cordon (see Figure 5).

Foundations were shuttered and then concreted using a pump in the front compound. Once the foundations had cured, a working platform of crushed stone was installed to give a constant level. Foundation anchors were drilled, resined in place and then tested. Towers were then erected from the west to the east using a $100 \mathrm{t}$ telescopic crawler crane working on the top of the working platform. As each tower was erected, the support brackets were fixed and welded in place. Once there were enough supports, the trusses were installed and welded to the brackets. The packing and ties were installed as the trusses were placed, although where access to the inside was hazardous, the ties were left out until the debris within was reduced to allow access.

Along the side elevations, the lack of space meant that the work had to proceed from west to east. As each bay was completed, the crane worked backwards towards Royal Avenue.

\section{Innovations}

Engineers are often challenged in their work as opportunities to innovate are limited by prescriptive standards and specifications. One of the challenges and opportunities presented by this scheme is that some of the issues have had to be dealt with in unusual ways due to the constraints of the scheme, and as such, it has been necessary to innovate to succeed. Fortunately, a helpful client and local authority have made these possible and the real benefits possible from innovation have been realised.

\subsection{Modelling of collapse mechanisms}

One of the challenges that were experienced was determining a safe distance for building the cordon and what loads that cordon would experience. While BS 6187 (BSI, 2011a) gives guidance on the requirement for exclusions zones, the size of those exclusion zones is not defined. Again, while there is much literature on the mechanisms of masonry failure, there is very little on the post-failure behaviour of the collapsing structure. This is clearly a rich field for research in the future.

However, given the timescale and safety concerns over the structure, it was necessary to determine several things quickly how far does falling debris go and how fast is it travelling before it gets there. From this range of values, it was possible to determine the design of the cordon, primarily the height and weight of the main components forming the protection screen.

Three approaches were adopted.

- It was assumed that the whole facade fluidised and spread over the width between the base of the wall and the cordon. This height was then doubled, and a load was derived equivalent to a fluid with the same density as the masonry.

- The independent checkers (Expedition) reviewed the collapse in line with the chimney collapse equations and dynamics, allied with physical modelling of large block collapses triggered at various heights through the facade (Figure 9).

- Discussions between the designer and checker led to appointing a further independent consultant (Ochsendorf, DeJong \& Block (ODB)) to model the collapse mechanism and failure behaviour using discrete element techniques (Figure 10).

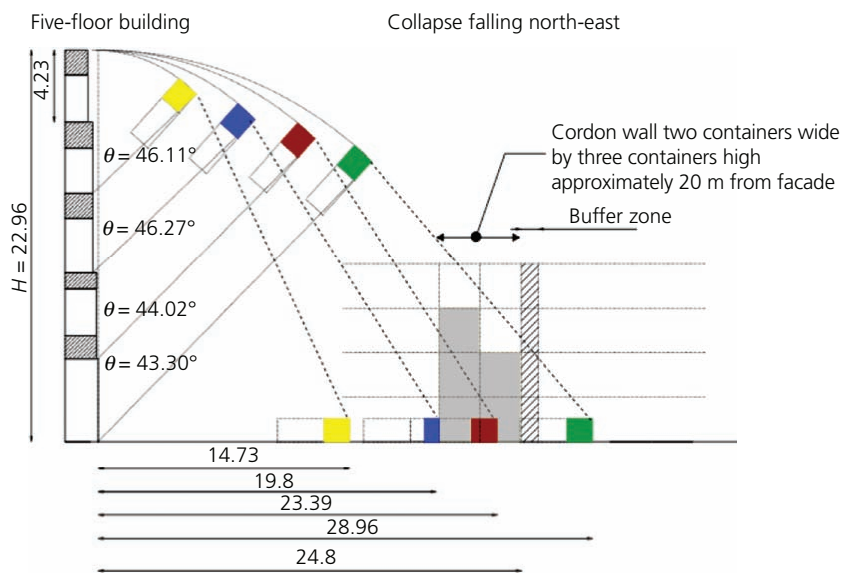

Figure 9. Extract from the Expedition report (Maccioni and Walsh, 2018) showing failure mechanisms and debris field (units are in $\mathrm{m}$ ) 
Forensic Engineering

Volume 172 Issue 3
Bank Buildings, Belfast, UK: making safe

after a fire

Lohmann and McClafferty
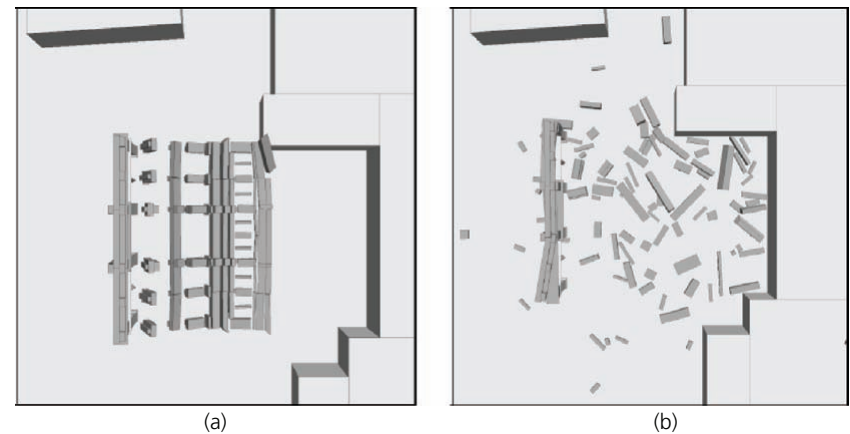

Figure 10. Extract from Figure 18 of the ODB report (DeJong, 2018) showing (a) the collapsed shape of front facade before impact and (b) the final debris field

When all of the team were comfortable with the proposed loading scenarios, the containment cordon was designed on that basis. This was through a review process with all of the main stakeholders.

\subsection{Three-dimensional scan of the facade}

One of the major challenges of installing facade-retention schemes is that the geometry of the facade is often not accurately known and that the resolution of the survey often misses detailed elements that later obstruct the installation of the facade members. If one is working in a stable structure and the existing support is not removed until after the retention system is installed, this can be a challenge. In some instances, the team has used 3D scanning to develop a true 3D model of the building and then built a virtual facade-retention system around this.

In Belfast, the opportunity of getting over these challenges was much harder to resolve, as the facade was not in good condition and had no support. Therefore, the solution had to work first time. The client was able to provide a high-quality $3 \mathrm{D}$ scan of the building, and the model of the facade was built around this, ensuring no clashes.

\subsection{Wind tunnel study of facade-retention system}

From previous experience, the use of the BS EN 1991-1-4 design code can give high values for the wind load on facade retentions, and for free-standing walls with lots of big openings, the code tends to give even higher loads. In addition, the site was in a complex area of a city near the sea. All of these factors both added uncertainty to the view of the wind on the scheme and potentially increased the wind load. In order to improve confidence in the actual loads on the structure, BRE were commissioned to undertake a wind tunnel study, and the results of this study (Figure 11) were then used for the design and checking of the facade-retention system.

\subsection{Fibre-reinforced foundations}

One of the challenges was that the team wanted to minimise the work done under the damaged facade prior to the erection of the

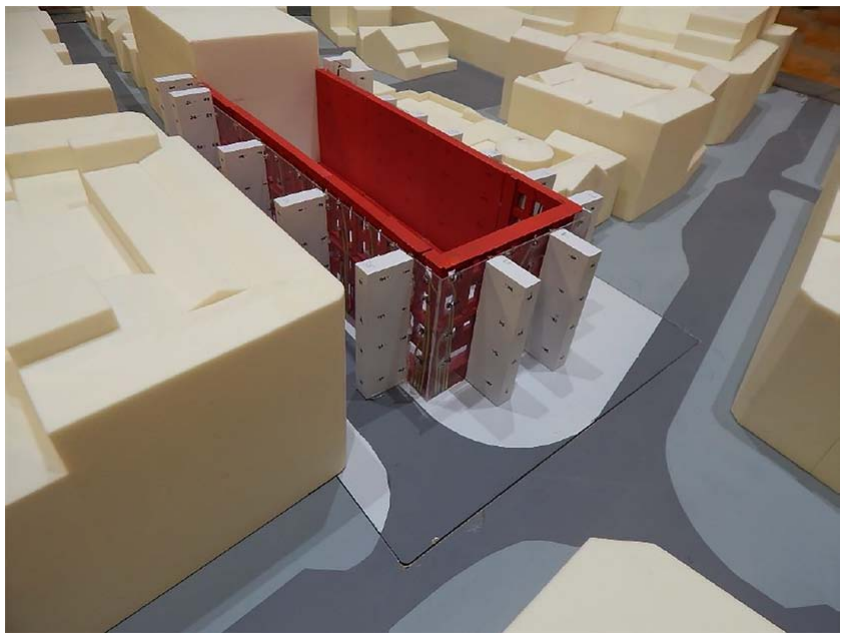

Figure 11. Wind tunnel model

facade-retention system. Relatively thick bases were needed to provide the distribution needed to limit ground bearing pressures and to provide the ballast for the towers. While these would normally be traditionally reinforced, the team took advantage of the depth of the sections and the consequently low flexural and shear stresses to go to a fully fibre-reinforced design. The concrete was specified as $\mathrm{C} 32 / 40$ and $35 \mathrm{~kg} / \mathrm{m}^{3}$ of steel fibres. These slabs were designed by the contractor to a performance specification based on bolt pull-out, corner reactions from the towers and shear and flexure in the pads. These were independently checked (Concrete Society, 2007).

The opportunity to avoid the use of bar reinforcement from the foundation slabs improved safety and gave cost and programme benefits. Pull-out tests were undertaken to verify the tensile capacity of resin-anchored bolts in this material.

\subsection{Use of shipping containers as structural components}

When the team was looking at solutions that gave simple connections and stackable components, it was obvious to look at shipping containers for the pedestrian protection cordon. Once the team had developed an understanding of them for this approach, the use of containers for the facade-retention system also made sense. There were some challenges with their use, as the lowerbound properties from the container standard did not provide enough lateral strength. However, the view was taken that the ability to ballast the towers through their height and to have simple connections outweighed the lateral strength issue. The racking challenge was dealt with by providing additional lateral bracing between the connector nodes.

The use of a widely available and reusable component for the main towers has been a great success, with complete towers being erected in a matter of hours. 


\section{Conclusions and acknowledgements}

The team was presented with a challenging problem in a complex environment. The work involved participants from many organisations, all of whom responded in a considered and helpful way while maintaining the interests of their stakeholders. These included the client, the main contractor, the client's design team and conservation specialists and the local authority. The team would like to take this opportunity to thank them all for their support and co-operation. Through an open and collaborative process, the team was able to develop solutions to many challenges, including the recording and dismantling for reuse of the fragile high-level elements, the development of a public safety cordon and the eventual facade-retention system and foundations.

In many ways, the constraints associated with the site and surroundings meant that the usual solutions were not feasible, and so the team was compelled to seek alternative solutions. The supportive team environment meant that it was possible to explore innovative solutions and approaches, which, it is believed, have added value to the scheme. While it is never good to have to respond to a catastrophe, it is important that the learning from these events is shared.

\section{REFERENCES}

BSI (2005) BS EN 1991-1-4:2005+A1:2010: Eurocode 1. Actions on structures. General actions. Wind actions. BSI, London, UK.

BSI (2011a) BS 6187:2011: Code of practice for full and partial demolition. BSI, London, UK.

BSI (2011b) BS 5975:2008+A1:2011: Code of practice for temporary works procedures and the permissible stress design of falsework. BSI, London, UK.

Bussell M, Lazarus D and Ross P (2003) Retention of Masonry Facades Best Practice Guide. Ciria, London, UK. C579.

Causeway Geotech (2018) Bank Buildings, Belfast - Ground Investigation. Causeway Geotech, Ballymoney, UK, 18-1403.

Ciria (Construction Industry Research and Information Association) (2019) Guide to Tower Crane Foundation and Tie Design. Ciria, London, UK. C761.

Concrete Society (2007) Guidance for the Design of Steel-fibre-reinforced Concrete. Concrete Society, Camberley, UK. Technical Report No. 63. DeJong M (2018) Collapse Assessment for Bank Building Belfast. Ochsendorf, DeJong \& Block LLC, Cambridge, MA, USA.

ISO (International Organization for Standardization) (1990) ISO 1496-1: Series 1 freight containers - specification and testing - part 1: general cargo containers for general purposes. ISO, Geneva, Switzerland.

Kusotova K and Breeze G (2019) XXXX Store, Belfast - Wind Loading Report. Building Research Establishment, Watford, UK. P113800-1000.

Maccioni A and Walsh S (2018) Bank Buildings Belfast Review of Cordon Containment Reduction. Expedition, London, UK. EXP-REP-1097001 rev01.

\section{How can you contribute?}

To discuss this paper, please email up to 500 words to the editor at journals@ice.org.uk. Your contribution will be forwarded to the author(s) for a reply and, if considered appropriate by the editorial board, it will be published as discussion in a future issue of the journal.

Proceedings journals rely entirely on contributions from the civil engineering profession (and allied disciplines). Information about how to submit your paper online is available at www.icevirtuallibrary.com/page/authors, where you will also find detailed author guidelines. 